\title{
A Rare Case Report of A Pulseless Male Patient With Sequale of Takayasu's Arteritis.
}

\author{
Dr. Bharat Veer Manchanda ${ }^{1}$, Dr. Saminder Chaudhary ${ }^{2}$, Dr. Saloni Mehra ${ }^{3}$, \\ Dr. Sonam Choudhary ${ }^{4}$, Dr. Girish Dubey ${ }^{5}$, Dr. Abhisar Bhatnagar ${ }^{6}$ \\ ${ }^{1}$ Assi. Professor In Dept Of Medicine, Subharti Medical College, Meerut \\ ${ }^{2,5,6}$ Post Graduate In Dept Of Medicine, Subharti Medical College, Meerut \\ ${ }^{3}$ Post Graduate In Dept Of Surgery, Subharti Medical College, Meerut \\ ${ }^{4}$ Post Graduate In Dept Of Obs. \&Gynae, Subharti Medical College, Meerut
}

\begin{abstract}
Cardiogenic embolism is a major cause of stroke and often leads to significant morbidity and mortality. Despite the recent advances in our understanding of the pathophysiology of stroke and its risk factors, diagnosis and therapy; some case scenarios still present a real challenge for the treating physicians. We report a case of a 38 year old male patient presenting with multi-territory cerebral infarctions due to a left ventricular mobile thrombus complicated by pulseless right arm later investigated and diagnosed to be takayasu's arteritis. Gradual introduction of anticoagulation and steroids coupled with a multidisciplinary team approach advocating careful daily clinical assessment of the patient and regular echocardiographic and neuroimaging studies have resulted in a better management and achievement of therapeutic goals.
\end{abstract}

Keywords: Stroke, Cardioembolism, Mobile thrombus, Takayasu's arteritis, Echocardiography, Multidisciplinary approach

\section{Introduction}

Embolic stroke is a leading cause of morbidity and mortality. The heart is an important source for the development of embolic strokes. About $15-20 \%$ of all ischemic strokes are cardioembolic. Establishing the heart as a source for a patient's embolic stroke carries important prognostic and therapeutic implications. Patients with such types of stroke often suffer significant morbidity and mortality and have a high risk of recurrence. The presence of takayasu's arteritis leading to coronary artery disease followed which a left ventricular thrombus, which carries additional risks including the risk of carotid atherosclerotic plaque. Managing patients of takayasu's arteritis along with left ventricular thrombi causing an embolic stroke as we present in this report.

\section{Case Report}

A 38-year old right-handed male with a history of smoking and alcohol for 20 years, presented with severe headache which was localised mainly to temporal region associated with vertigo, followed by blurring of vision since 9 days and slurring of speech along with right sided weakness since 5 days. He had no history of chest pain or palpitations. He did, however, give a history of a recent visit to another medical practitioner for the same but did not get any relief. Details of his management during that visit were not available. Examination showed blood pressure on left hand in supine position of 140/90 $\mathrm{mmHg}$, regular heart rate of 90 per minute, and no peripheral pulse on right hand, \&clubbing grade 3, bruit over carotid and subclavian artery and Glassgow coma scale (GCS) of 15, expressive aphasia, with right sided hemiparesis and left homonymous hemianopsia . Cardiac examination as well as ECG, cardiac enzymes and basic laboratory investigations was unremarkable. Initial CT brain showed a occipital infarct and fronto temporal infract on left side. B/l carotidcolour Dopplershowed soft plaque in cca \& ica on right side intima media thickened in the arteries of the neck and decreased velocity in cca ,ica\& eca.The patient was admitted to the high dependency unit of the general medical ward with regular assessment of his GCS.

The patient's initial CT brain showed multiple areas of ischemic infarcts, the largest of which is in the distribution of the leftt middle \& posterior cerebral artery.

Echocardiography revealed poor overall systolic function (ejection fraction $20 \%$ ) with global hypokinesia,severe lv dysfunction and a mobile thrombus measuring about $2.6 \mathrm{~cm} \times 1.4 \mathrm{~cm}$ in the apical region of the left ventricle. The patient was started on $100 \mathrm{ml}$ of Mannitol $20 \%$ three times daily with daily monitoring of the electrolytes profile in addition to regular physiotherapy. Forty-eight hours after the onset, he was started on weight-adjusted low molecular weight heparin (LMWH) at a prophylactic dose (enoxaparin $40 \mathrm{mg} / \mathrm{day}$ ) and clopidogrel $75 \mathrm{mg}$ once a day. He had minimal improvement in his neurological status. His thrombophilia workup (including tests for protein $\mathrm{S}$, protein $\mathrm{C}$ and anti-thrombin levels and activities sent before the initiation 
of LMWH, as well as molecular testing for factor $\mathrm{V}$ Leiden and prothrombin gene mutations) were unremarkable.

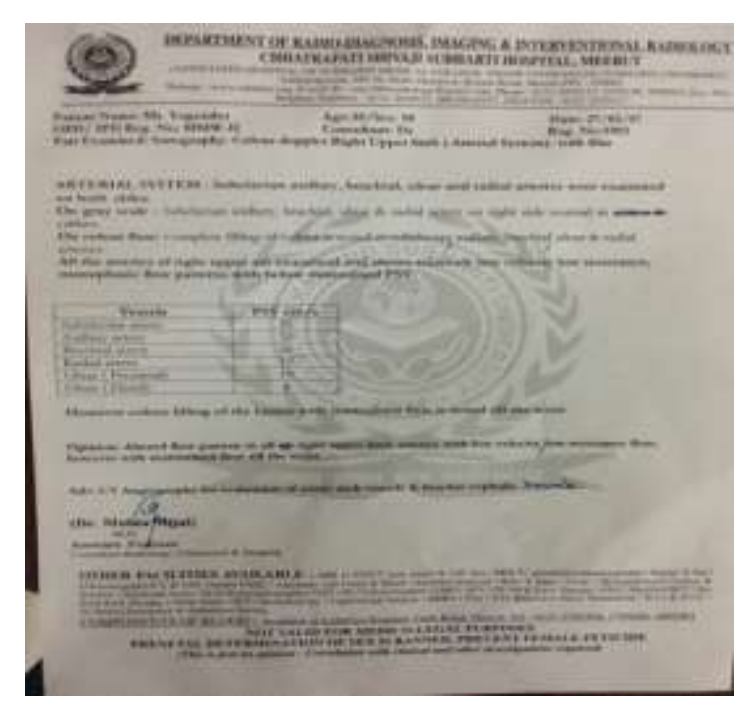

Doppler Report

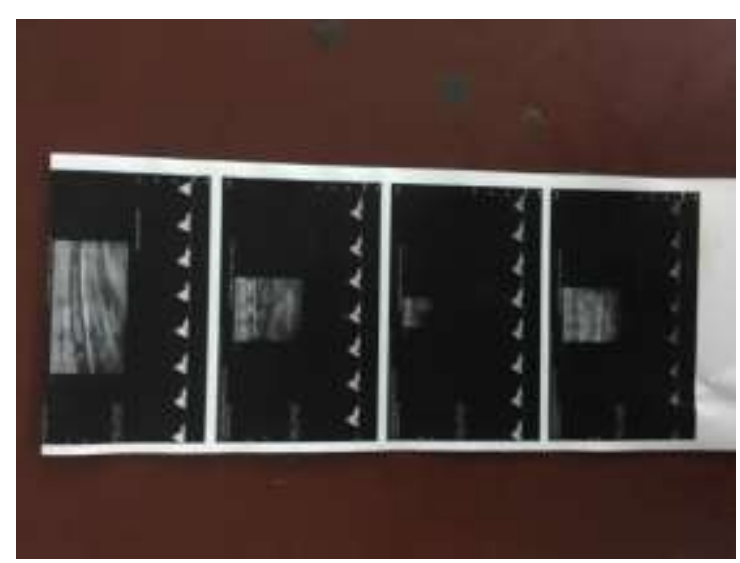

Echo showing the LV thrombus.

Patient was further evaluated for the pulseless right arm by doing Colour Doppler of the right arm in order to rule out takayasu's arteritis, which showed reduced blood flow velocity, low resistance and vessel wall thickening.

Daily assessment of the patient by a multi-disciplinary team including a neurologist, a cardiologist and a hematologist in addition to the primary internist was adopted. A weekly echocardiogram was used to assess the thrombus size while weekly neuro-imaging with CT scans was initially used to assess the infracted areas, especially with regards to hemorrhagic transformation. With no progression in the small areas of hemorrhagic transformation on CT scans, the dose of enoxaparin was upgraded to $40 \mathrm{mg}$ twice daily and then after another week, it was increased to $60 \mathrm{mg}$ twice daily with weekly monitoring of anti-Xa levels. Warfarin was introduced with a target INR of 2.0 to 3.0. Follow up echocardiographic studies demonstrated a significant regression in the thrombus size without any evidence of further systemic embolization. The patient was discharged after 7 weeks of hospitalization with NIH Stroke Scale score of 15 and a modified Rankin Scale score of 5.

\section{Discussion}

Cardiogenic embolism is recognized to account for one in six strokes ${ }^{1,2}$. Common causes of cardiac embolization include atrial fibrillation, ischemic heart disease, rheumatic heart disease and prosthetic cardiac valves $^{3,4,5,6}$. Left ventricular thrombi (a frequent complication of transmural acute myocardial infarction, likely to be the case in our patient) $)^{7,8}$, are second to atrial thrombi from atrial fibrillation as a cause of cardiogenic embolization. These are easily detectable by two-dimensional echocardiography, although false-positive studies exist ${ }^{9}$.Protruding configuration and free mobility of the thrombus and the presence of adjacent hypokinesia indicate a high embolization potential ${ }^{10,11}$. The presence of a potential embolic source does not, by itself, justify 
the diagnosis of cardiogenic embolism in this patient. However, the abrupt onset of maximal deficit, the presence of multiple brain infarcts involving different vascular territories along with the presence of a large left ventricular thrombus indicate that the cause of the infarcts in this patient are indeed cardioembolic.

Takayasu's disease is histologically characterized by irregular thickening of the aortic wall and its branches. Early lesions consist of a mononuclear infiltrate of the vascular adventitial vasa vasorum. Later, there may be marked mononuclear infiltrate of the arterial media, accompanied in some cases by granulomatous lesions filled with giant cells and patchy media necrosis. With disease progression even after treatment with steroids, inflammatory reaction is predominantly characterized by collagen fibrosis affecting all layers of the vessel wall (especially the intima) accompanied by lymphocytic infiltration. This is the mechanism by which constrictions of the coronary arteries may lead to AMI ${ }^{12}$.

1990 Criteria of American College of Rheumatology for the Classification of Takayasu Arteritis
\begin{tabular}{|l|l|}
\hline Criteria & Definition \\
\hline Age at disease onset in year & $\begin{array}{l}\text { Development of symptoms or findings related to Takayasu } \\
\text { arteritis at age }<40 \text { years. }\end{array}$ \\
\hline Claudication of extremities & $\begin{array}{l}\text { Development and worsening of fatigue and discomfort in } \\
\text { muscles of one or more extremity while in use, especially the } \\
\text { upper extremities. }\end{array}$ \\
\hline Decreased brachial artery pulse & Decreased pulsation of one or both brachial arteries \\
\hline BP difference $>10 \mathrm{mmHg}$ & $\begin{array}{l}\text { Difference of }>10 \mathrm{mmHg} \text { in systolic blood pressure between } \\
\text { arms }\end{array}$ \\
\hline $\begin{array}{l}\text { Bruit over subclavian arteries or } \\
\text { aorta }\end{array}$ & $\begin{array}{l}\text { Bruit audible on auscultation over one or both subclavian } \\
\text { arteries or abdominal aorta }\end{array}$ \\
\hline Arteriogram abnormality & $\begin{array}{l}\text { Arteriographic narrowing or occlusion of the entire aorta, its } \\
\text { primary branches, or large arteries in the proximal uppper or } \\
\text { lower extremities, not due arteriosclerosis, fibro-muscular } \\
\text { dysplasia, or similar causes: changes usually focal or segmental }\end{array}$ \\
\hline
\end{tabular}

The cause of coronary artery disease in a young patient with a pulseless right arm was further evaluated and was to our surprise a rare entity Takayasu's arteritis. Being such a rare presentation came to us a challenge, which further evaluated with the help of imaging techniques.

Upon discharge our patient was treated with warfarin $2 \mathrm{mg} /$ day(to keep inr in a range of 2-3), aspirin $100 \mathrm{mg} /$ day, methylprednisolone $40 \mathrm{mg} /$ day, clopidogrel $75 \mathrm{mg} /$ day, amlodipine $10 \mathrm{mg}$ every 12 hours, nebivolol $10 \mathrm{mg} /$ day, hydrochlorothiazide $25 \mathrm{mg} /$ day and pantoprazole $40 \mathrm{mg} / \mathrm{day}$ and the association with cyclosporine was recommended.

\section{Conclusion}

The clinical presentation of patients with Takayasu's arteritis can be as varied as the location of the affected arteries. The cases presented with AMI described in the literature are rare; in the case of our patient it was an Anterior AMI. Left ventricular thrombus complicating ischemic heart disease and causing systemic embolism is a well-recognized clinical phenomenon which requires anticoagulation. The treatments should be focused not only to prevent progression of the disease, but also to improve the quality of life. From the beginning treatment has been based on corticosteroids, oral anticoagulants, which may be associated with immunosuppressants such as cyclosporin. Early diagnosis and optimal treatment play a key role in the patient's outcome and disease progression.

\section{References}

[1]. Mohr JP, Caplan LR, Melski JW, Goldstein RJ, Duncan GW, Kistler JP, et al. The Harvard Cooperative Stroke Registry: a prospective registry. Neurology 1978. Aug;28(8):754-762 10.1212/WNL.28.8.754

[2]. Robertson JT. Neck manipulation as a cause of stroke. Stroke 1981. Jan-Feb;12(1):1 10.1161/01.STR.12.1.1

[3]. Cerebral Embolism Task Force Cardiogenic brain embolism. Arch Neurol 1986. Jan;43(1):71-84 10.1001/archneur.1986.00520010065026

[4]. Cerebral Embolism Task Force Cardiogenic brain embolism. The second report of the Cerebral Embolism Task Force. Arch Neurol 1989. Jul;46(7):727-743 10.1001/archneur.1989.00520430021013

[5]. Stratton JR. Common causes of cardiac emboli-left ventricular thrombi and atrial fibrillation. West J Med 1989. Aug;151(2):172179

[6]. Pujadas Capmany R, Arboix A, Casañas-Muñoz R, Anguera-Ferrando N. Specific cardiac disorders in 402 consecutive patients with ischaemic cardioembolic stroke. Int J Cardiol 2004. Jun;95(2-3):129-134 10.1016/j.ijcard.2003.02.007

[7]. Stokman PJ, Nandra CS, Asinger RW. Left Ventricular Thrombus. Curr Treat Options Cardiovasc Med 2001. Dec;3(6):515-521 10.1007/s11936-001-0025-6

[8]. Easton JD, Sherman DG. Management of cerebral embolism of cardiac origin. Stroke 1980. Sep-Oct;11(5):433-442 10.1161/01.STR.11.5.433

[9]. Stratton JR, Lighty GW, Jr, Pearlman AS, Ritchie JL. Detection of left ventricular thrombus by two-dimensional echocardiography: sensitivity, specificity, and causes of uncertainty. Circulation 1982. Jul;66(1):156-166 10.1161/01.CIR.66.1.156 
[10]. Visser CA, Kan G, Meltzer RS, Dunning AJ, Roelandt J. Embolic potential of left ventricular thrombus after myocardial infarction: a two-dimensional echocardiographic study of 119 patients. J Am Coll Cardiol 1985. Jun;5(6):1276-1280 10.1016/S07351097(85)80336-3

[11]. Jugdutt BI, Sivaram CA. Prospective two-dimensional echocardiographic evaluation of left ventricular thrombus and embolism after acute myocardial infarction. J Am Coll Cardiol 1989. Mar;13(3):554-564 10.1016/0735-1097(89)90592-5

[12]. Arend WP, Michel BA, Bloch DA, Hunder GG, Calabrese LH, Edworthy SM, et al. The American College of Rheumatology 1990 criteria for the classification of Takayasu arteritis. Arthritis Rheum 1990, 33:1129-34. 